\title{
OPTIMIZATION OF HIGH-PERFORMANCE CONCRETE POST-TENSIONED BOX-GIRDER PEDESTRIAN BRIDGES
}

\author{
VÍCTOR YEPES ${ }^{1,3}$, ELOY PÉREZ-LÓPEZ ${ }^{2}$, TATIANA GARCÍA-SEGURA ${ }^{3}$ \& JULIÁN ALCALÁ ${ }^{1,3}$ \\ ${ }^{1}$ Institute of Concrete, Science and Technology (ICITECH), Universitat Politècnica de València, Spain. \\ ${ }^{2}$ Offshore Renewable Energy Engineering Centre, SEEA, Cranfield University, United Kingdom. \\ ${ }^{3}$ Dept. Ingeniería de la Construcción, Universitat Politècnica de València, Spain.
}

\begin{abstract}
This paper deals with the economic optimization of high-performance post-tensioned concrete boxgirder pedestrian bridges. To this end, a program analyzes and evaluates the structural restrictions following Spanish codes for structural concrete and bridge design loads. This problem includes 33 discrete design variables that define the geometry, the concrete, the reinforcing steel bars and the post-tensioned steel. Various acceptance criteria are proposed to modify a variant of the simulated annealing algorithm with a neighborhood move based on the mutation operator from the genetic algorithms (SAMO). An objective methodology based on the extreme value theory is used to determine the number of experimental tests required to provide a solution with user-defined accuracy as compared to a global optimum solution. Results indicate that the local optima found by SAMO2 fits a threeparameter Weibull distribution and improves the cost results for this structural problem. The minimum value obtained by SAMO2 differed just $0.34 \%$ compared to the theoretical minimum value so that, from the structural engineering perspective, the divergence was small enough to be accepted. Highstrength concrete performance was further studied in a concrete strength parametric study to acquire more evidence-based knowledge on its implications for economic efficiency. Finally, the study showed that high-strength concrete decreases the cost by $4.5 \%$ and the amount of concrete by $26 \%$.

Keywords: box-girder bridge, extreme value theory, high-strength concrete, post-tensioned concrete, simulated annealing, Structural optimization
\end{abstract}

\section{INTRODUCTION}

Structural engineering aims to achieve the maximum safety with the minimum investment. This target is not easy as long as the structural problem is characterized by a wide variety of variables with multiple combinations. First, the bridge designer has to decide the over-all structural design according to the topographical and traffic conditions. Then, the cross section geometry and the type and distribution of the materials are defined based on design criteria and professional experience [1]. Finally, the last variables are adjusted to guarantee structural safety. Researchers have explored new ways to achieve the structural efficiency. Aparicio et al. [2] presented a computer-aided design to identify the most effective prestressed concrete bridges. Hassanain and Loov [3] provided a review of the optimization techniques applied to concrete bridges. Penadés-Plà et al. [4] conducted a review of the decision-making methods used to achieve a sustainable bridge design. However, Hernández et al. [5] pointed that most of the approaches found in the literature were not suitable to be implemented in real life bridge engineering.

Cohn and Dinovitzer [6] provided an extensive state-of-the-practice in structural optimization; in this study, they brought out the gap between theoretical aspects and practical problems of structural optimization. Metaheuristic algorithms guide the search for the better solution based on certain governing rules. Much research has been conducted recently with regard to meta-heuristics applied to structural optimization such as glowworm swarm algorithm [7], harmony search [8], bat-inspired algorithm [9], lion pride optimization [10], particle swarm optimization [11], firefly algorithm [12], among others. In this context, the 
present authors' research group reported on simulated annealing (SA) based techniques to optimize road vaults [13], bridge piers [14], abutments road bridges [15], I-beams [16] and prestressed concrete bridges [17].

This study employs a hybrid SA algorithm with mutation operator and different acceptance criteria to find the best designs for a three-span deck. For this purpose, a program encompasses modules for structural analysis, limit states verification and cost evaluation. In addition to the above, the use of other materials, like high-strength concrete, can alter the design criteria [18, 19]. The use of high-strength concrete reduces self-weight and, therefore, the amount of concrete and steel required. The study not only shows the applicability of the algorithm to the structure, but also provides engineers with guidelines for the efficient design.

\section{OPTIMIZATION PROBLEM DEFINITION}

\subsection{Problem formulation}

This study aims to minimize the cost of a pedestrian deck bridge, which is defined by design variables $\left(x_{1}, x_{2} \ldots x_{n}\right)$. The problem involves an objective function $F$ of Eq. (1), subject to the constraints represented by Eq. (2). The program analyzes and evaluates the cost of a continuous beam deck with a box-girder cross section of post-tensioned concrete. Then, the program gives the best design.

$$
\begin{gathered}
\mathrm{F}\left(x_{1}, x_{2}, \ldots . x_{n}\right) . \\
G_{j}\left(x_{1}, x_{2}, \ldots . . x_{n}\right) \leq 0 .
\end{gathered}
$$

The objective function evaluates the cost of the total number of construction units $(r)$, considering material and placement costs listed in Eq. (3). Unit prices $\left(p_{i}\right)$, shown in Table 1, were obtained from the BEDEC ITEC database [20].

Table 1: Basic prices

\begin{tabular}{lc}
\hline Unit measurements & Cost $(€)$ \\
\hline $\mathrm{m}^{3}$ of scaffolding & 10.02 \\
$\mathrm{~m}^{2}$ of formwork & 33.81 \\
$\mathrm{~m}^{3}$ of lighting & 104.57 \\
$\mathrm{~kg}$ of steel (B-500-S) & 1.16 \\
$\mathrm{~kg}$ of post-tensioned steel (Y1860-S7) & 3.40 \\
$\mathrm{~m}^{3}$ of concrete HP-35 & 104.57 \\
$\mathrm{~m}^{3}$ of concrete HP-40 & 109.33 \\
$\mathrm{~m}^{3}$ of concrete HP-45 & 114.10 \\
$\mathrm{~m}^{3}$ of concrete HP-50 & 118.87 \\
$\mathrm{~m}^{3}$ of concrete HP-55 & 123.64 \\
$\mathrm{~m}^{3}$ of concrete HP-60 & 128.41 \\
$\mathrm{~m}^{3}$ of concrete HP-70 & 137.95 \\
$\mathrm{~m}^{3}$ of concrete HP-80 & 147.49 \\
$\mathrm{~m}^{3}$ of concrete HP-90 & 157.02 \\
$\mathrm{~m}^{3}$ of concrete HP-100 & 166.56 \\
\hline
\end{tabular}


Concrete unit prices were determined for each compressive strength grade according to the mix design, including the cost of raw materials extraction, manufacture and transportation. The measurements $\left(m_{i}\right)$ concerning the construction units depend on the design variables.

$$
C=\sum_{i=1, r} p_{i} \times m_{i}\left(x_{1}, x_{2,}, \ldots, x_{n}\right) .
$$

\subsection{Structural design}

The parameters and design variables are required to define the structural solution. The parameters define the overall geometry, the materials, the loads acting on the structure, the exposure class, and the code followed by this study (Table 2).

This study examines decks with three spans and a low height. Therefore, traditional scaffolding is used in the construction. The three spans into which the deck length is split follow

Table 2: Main parameters of the analysis

\section{Geometrical parameters}

Pedestrian bridge width

Number of spans

Central span length

External span length

Clearance

Diaphragm thickness

\section{Material parameters}

Maximum aggregate size

Reinforcing steel

Post-tensioned steel

Strand diameter

Tensioning time

\section{Loading related parameters}

Reinforced concrete self-weight

Asphalt layer self-weight

Mean asphalt thickness

Bridge railing self-weight

Live load

Differential settling

\section{Exposure related parameters}

External ambient conditions

Code related parameters

Code regulation

Service working life

$$
\begin{aligned}
& A=3.5 \mathrm{~m} \\
& 3 \\
& \mathrm{~L} 1=30-40-50-55-60 \mathrm{~m} \\
& \mathrm{~L} 2=24-32-40-44-48 \mathrm{~m} \\
& 5 \mathrm{~m} \\
& 1.2 \mathrm{~m}
\end{aligned}
$$
$20 \mathrm{~mm}$
B-500-S
Y1860-S7
$\Phi_{\mathrm{s}}=0.6 "$
7 days

$25 \mathrm{kN} / \mathrm{m}^{3}$

$24 \mathrm{kN} / \mathrm{m}^{3}$

$47.5 \mathrm{~mm}$

$1 \mathrm{kN} / \mathrm{m}$

$4 \mathrm{kN} / \mathrm{m}^{2}$

$5 \mathrm{~mm}$
IIb

EHE-08/IAP-98

100 years 
the relation that the external span is $80 \%$ of the central. The pedestrian bridge is $3.5 \mathrm{~m}$ wide. 33 variables define the geometry, the concrete, the reinforcing steel bars and the post-tensioned steel. The first seven variables are geometrical (Fig. 1): the depth $(h)$, the width of the bottom slab $(b)$, the width of the web inclination $(d)$, the thickness of the top slab $\left(e_{s}\right)$, the thickness of the external flange section $\left(e_{v}\right)$, the thickness of the bottom slab $\left(e_{i}\right)$, and the thickness of the webs $\left(e_{a}\right)$. This study proposes $15 \mathrm{~cm}$ as the minimum thickness. Other geometrical values, like the haunch $(t)$, are calculated from the values of other variables (Eq. (4)) according to Schlaich and Scheff's [21] recommendations. Additionally, the haunch must provide the space to contain the ducts in the high and low points.

$$
t=\max \left\{\frac{b-2 * e_{a}}{5}, e_{i}\right\} .
$$

The variable $f_{c k}$ defines the concrete strength, which ranges between $35 \mathrm{MPa}$ and $100 \mathrm{MPa}$. The post-tensioned steel formed by 0.6 inch strands is prestressed to $195.52 \mathrm{kN}$. The ducts are symmetrically distributed through the webs by a parabolic layout. The maximum eccentricity is presented where the bending moment is the maximum or minimum (Fig. 2). At these points, the distance between the duct and the reinforcing bars is 1.5 times the duct diameter. The following variables determine the distance from the piers to the point of inflection $\left(L_{P I}\right)$ and the number of strands $\left(N_{S}\right)$.

Reinforcing steel is defined by 23 variables, 15 for the longitudinal reinforcement and eight for the transverse reinforcement (Fig. 1). Longitudinal reinforcement is defined by the number of bars per meter and the diameter, placed at the top slab $\left(L R_{n 1}, L R_{\varnothing 1}\right)$, the flange top face $\left(L R_{n 2}, L R_{\emptyset 2}\right)$, the flange bottom face $\left(L R_{n 3}, L R_{\emptyset 3}\right)$, the web $\left(L R_{n 4}, L R_{\emptyset 4}\right)$, the bottom slab $\left(L R_{n 5}, L R_{\varnothing 5}\right)$ and the core $\left(L R_{n 6}, L R_{\varnothing 6}\right)$. Besides, extra bending reinforcement is divided into two systems. One covers the top slab at the support zone ( $L / 5$ on both sides of the piers), with a diameter defined by $L R_{\varnothing 7}$ and the same number of bars per meter as $L R_{n 1}$. The other is placed at the bottom slab throughout the rest of the external span $\left(L R_{\varnothing 8}\right)$ and central span $\left(L R_{\varnothing 9}\right)$. The number of bars per meter is, for both locations, equal to $L R_{n 5}$. The diameter can change among $0,10,12,16,20,25$ and $32 \mathrm{~mm}$. Regarding transverse reinforcement, the diameter of the standard reinforcement $\left(T R_{\varnothing 1,} T R_{\varnothing 2,} T R_{\varnothing 3,} T R_{\varnothing 4,} T R_{\varnothing 5,} T R_{\varnothing 6,} T R_{\varnothing 7}\right)$ is set with the same spacing $\left(T R_{S}\right)$.

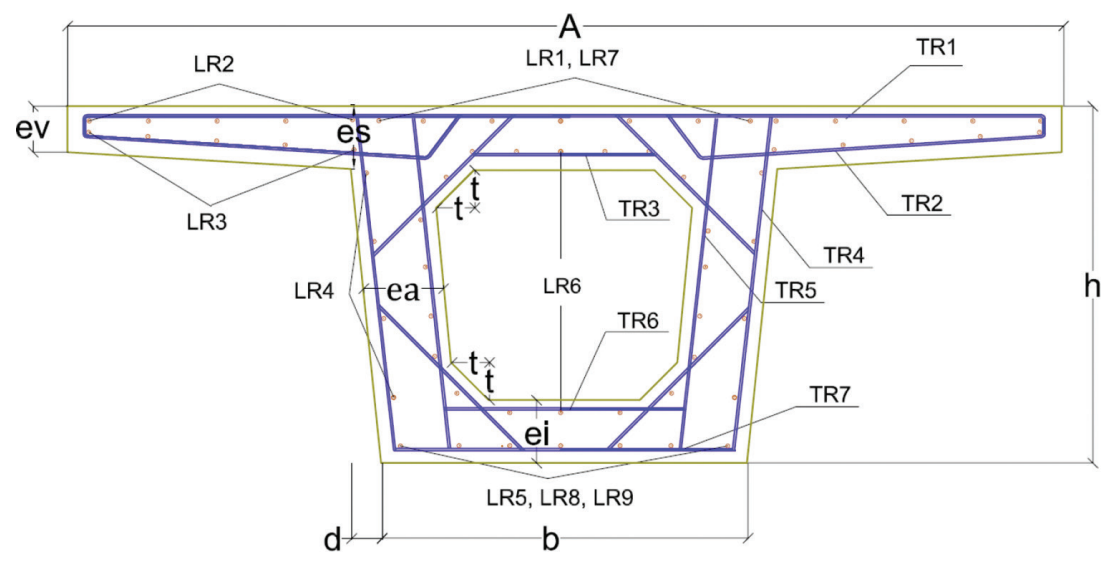

Figure 1: Box-girder cross section 


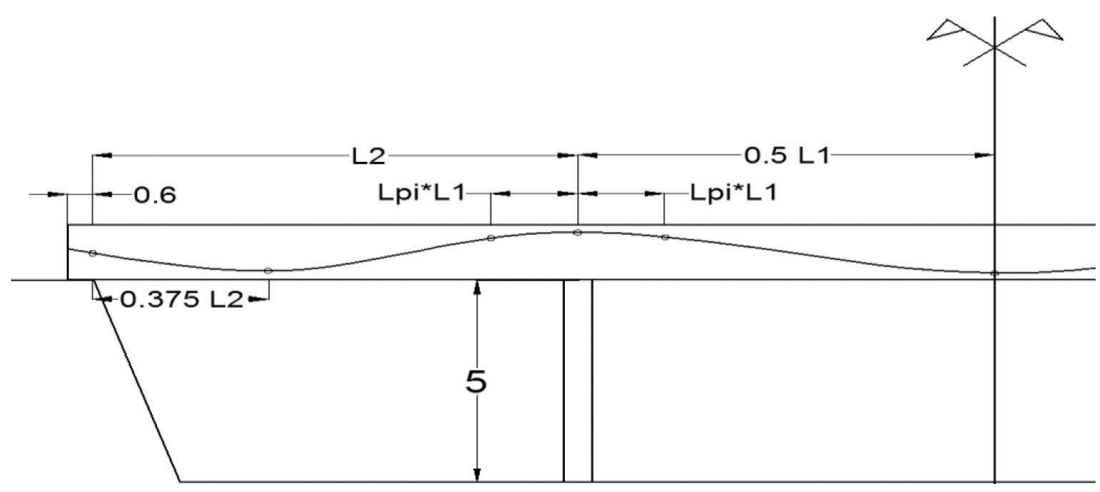

Figure 2: Pedestrian bridge and duct layout

\subsection{Structural evaluation module}

The structural constraints represented by Eq. (2) check the serviceability and ultimate limit states (SLS and ULS) and the geometrical and constructability requirements [22, 23]. Prior to verification, the values of the variables are set and the structural evaluation module calculates the stress envelopes. The structural model takes into account shear deformation and effective flange width [24]. The structure was modelled by a linear element with 30 bars, 31 sections and 93 degrees of freedom. Transverse analysis was carried out using a frame model. The loads considered are the live load and the deck self-weight including the bridge railing and asphalt (see Table 2). Furthermore, this modulus takes into account the thermal gradient, the prestressing steel effect and differential settling in each pier.

The evaluating process differs from the standard method, since the latter is an iterative procedure. First, the cross section is chosen according to the experience. Then, the steel is set according to ULS and SLS restrictions. Using heuristic optimization, any combination of geometry and steel is examined for SLSs and ULSs. Heuristic algorithms are capable of finding the proper design variables, which minimize the cost and guarantee structural safety. For instance, these algorithms can find new economic solutions suppressing shear reinforcement by increasing the flexural.

The SLS of cracking requires compliance of the crack width limitation for the durability conditions. The same module verifies the appearance of compression cracks and whether the post-tensioned steel is located in the compression area of the section. The deflection, both after the tensioning time and long-time, was limited to 1/500th of the free main span length for the characteristic combination. The long-time deflection is the sum of the instantaneous and time-dependent deflection, which considers concrete creep, shrinkage and the post-tensioned steel relaxation. The vibration limit state, due to the rhythmic step of pedestrians, ensures that the first mode frequency is more than $5 \mathrm{~Hz}$. Otherwise, the static deflection produced by a $75 \mathrm{~kg}$ pedestrian ( $\left.y_{e}\right)$ must comply with Eq. (5) [23].

$$
y_{e} \leq \frac{0.5 * \sqrt{f_{0}}}{4 * \pi^{2} * f_{0}^{2} * k * \psi} .
$$

where $k$ is 0.8 for 3 spans with a length relation of 0.8 and $\psi$ depends on the material and the main span length. For prestressed concrete with a span length of $30 \mathrm{~m}, 40 \mathrm{~m}$ and $50 \mathrm{~m}, \psi$ is $8.7,9.8$ and 10.8 , respectively. 
The ULS of flexure calculates the ultimate iteration diagram $\mathrm{Nu}-\mathrm{Mu}$ and then checks whether the acting bending resultant $M d$ is in the diagram. The shear, torsional and longitudinal shear limit states are verified similarly, as the ultimate force is greater or equal to the working stress. Likewise, the effect of torsion combined with bending and shear is checked. Meanwhile, the minimum amount of reinforcement for stress requirements and the geometrical condition are also examined.

\section{OPTIMIZATION ALGORITHMS}

This paper uses a hybrid SA algorithm with a mutation operator (SAMO). SAMO takes both of the advantages of good convergence in simulated annealing and enhancing diversity of genetic strategy. SA was originally proposed by Kirkpatrick et al. [25] and Černý [26] based on the analogy of crystal formation. A complete review of the method, along with some practical suggestions, can be found in Dreo et al. [27].The probability of acquiring a thermal state is proportional to the expression $(-E(\mu) / T)$, where $E(\mu)$ is the energy and $T$ the temperature. The algorithm starts with a feasible solution randomly generated and a high initial temperature. The initial working solution is modified by a small random move of the values of the variables. This problem takes parallelism with the probability of adopting worse solutions. Genetic algorithms are population-search procedures based on the process of natural evolution. This algorithm use operators such as selection, crossover and mutation [28]. The success as an optimization method in diverse engineering areas, particularly in structural engineering, has been proved [29]. Some authors have effectively combined both algorithms [30, 31].

SAMO was proposed by Martí et al. [30]. However, we studied five variations with different probability transition rules (Eq. (6-10)). All of these methods accept worse solutions when the increment is lower than a value, which depends on the temperature and a stochastic variable. Therefore, this probabilistic jumping property facilitates global optimum searching.

$$
\begin{aligned}
& p_{\text {SAMO1 }}=\min \left(1, e^{-\frac{\Delta E}{T}}\right) . \\
& p_{\text {SAMO2 }}=\frac{1}{1+e^{\frac{\Delta E}{T}}} \cdot \\
& p_{\text {SAMO3 }}=\min \left(1,1-\operatorname{erf}\left(\frac{\Delta E}{T \sqrt{2}}\right)\right) . \\
& p_{\text {SAMO4 }}=0.5 *\left(1-\operatorname{erf}\left(\frac{\Delta E}{T \sqrt{2}}\right)\right) . \\
& p_{\text {SAMO5 }}=\min \left(1,\left(\sqrt{\frac{\Delta E}{T}}+1\right) * e^{-\sqrt{\frac{\Delta E}{T}}}\right) .
\end{aligned}
$$

The temperature is the parameter in charge of adjusting the number of acceptances. The SA method is capable of surpassing local optima at high-medium temperatures and gradually converges as the temperature falls to zero. The SA method requires the calibration of the initial temperature, the length of the Markov chains and the cooling coefficient. The initial 
temperature is calibrated following Medina's method [32], which proposes that initial temperature is halved when the percentage of acceptances is greater than $40 \%$, and doubled when it is less than $20 \%$. After that, the temperature decreases according to a coefficient of cooling $k$ following the equation $(T=K \cdot T)$, when a Markov chain ends. The algorithm finishes after three Markov chains without improvement.

\section{RESULTS FROM COMPUTATIONAL EXPERIMENTS}

In this Section, we examine the results from computational experiments involving SAMO optimization applied to a post-tensioned concrete box-girder pedestrian bridge for a $50 \mathrm{~m}$ main-span deck, considering the parameters defined in Table 2. The algorithm was programmed in MATLAB with an INTEL® CoreTM i7-3820 CPU processor and 3.6 GHz. The calibration recommended SAMO2 criterion (see Table 3) with Markov chains of 5000 iterations and a cooling coefficient of 0.8 . Both mean and minimum cost obtained the best results for this criterion. Although the computing time is higher, the SAMO2 criterion was chosen because of its efficiency. The best move found was a random variation of up to $50 \%$ of the variables.

We applied a methodology based on extreme value theory $[33,34]$ to validate the algorithm and set a number of runs. If the statistical distribution of the local optima given by the SAMO2 algorithm proposed in this study fits a three-parameter Weibull distribution, then the estimated location parameter $\gamma$ can be used as an estimation of the global optimum. The program was run nine times to obtain statistical results, according to this methodology. The histogram for the sample of 500 minimal cost solutions found by SAMO2 is given in Fig. 3. The location parameter of this sample is $\gamma=€ 150534.46$. This value is what the SAMO2 algorithm estimated to be provided for the global optimum of the problem using the EVT. The other parameters obtained for the regression on Y were $\eta=2210.6203$ and $\beta=1.4908$. The Weibull fit had a correlation coefficient of $\rho=0.9666$, which was high enough for numerical results. The difference between the minimum cost obtained after nine runs and the extreme value estimated was $€ 509.53$, a difference of just $0.34 \%$ compared to the theoretical minimum value. From the point of view of the structural engineer, this indicates that the difference is small enough to make the solution provided by the proposed SAMO2 acceptable.

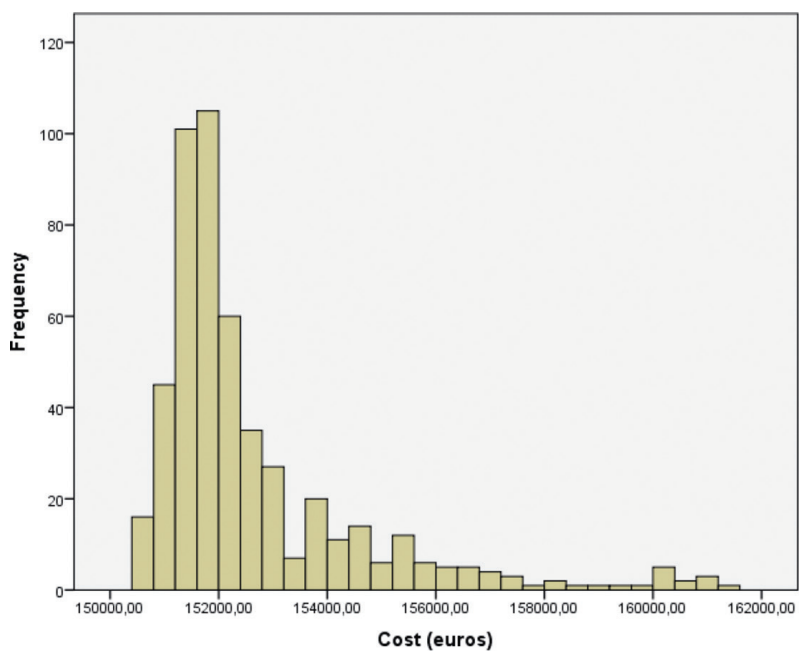

Figure 3: Histogram showing 500 cost-optimized SAMO2 results 
Table 3: Statistical results for the acceptance criterion

\begin{tabular}{lllll}
\hline Method & $\begin{array}{l}\text { Mean computing } \\
\text { time (sec.) }\end{array}$ & Mean cost $(€)$ & Minimum cost $(€)$ & Standard deviation $(€)$ \\
\hline SAMO1 & 11178.58 & 153539.26 & 151266.87 & 1943.75 \\
SAMO2 & 14190.24 & 153146.55 & 151043.99 & 1681.64 \\
SAMO3 & 13213.48 & 156010.79 & 152111.08 & 1706.51 \\
SAMO4 & 16052.67 & 155053.29 & 151545.17 & 4637.72 \\
SAMO5 & 7038.01 & 157227.88 & 152083.00 & 5457.30 \\
\hline
\end{tabular}

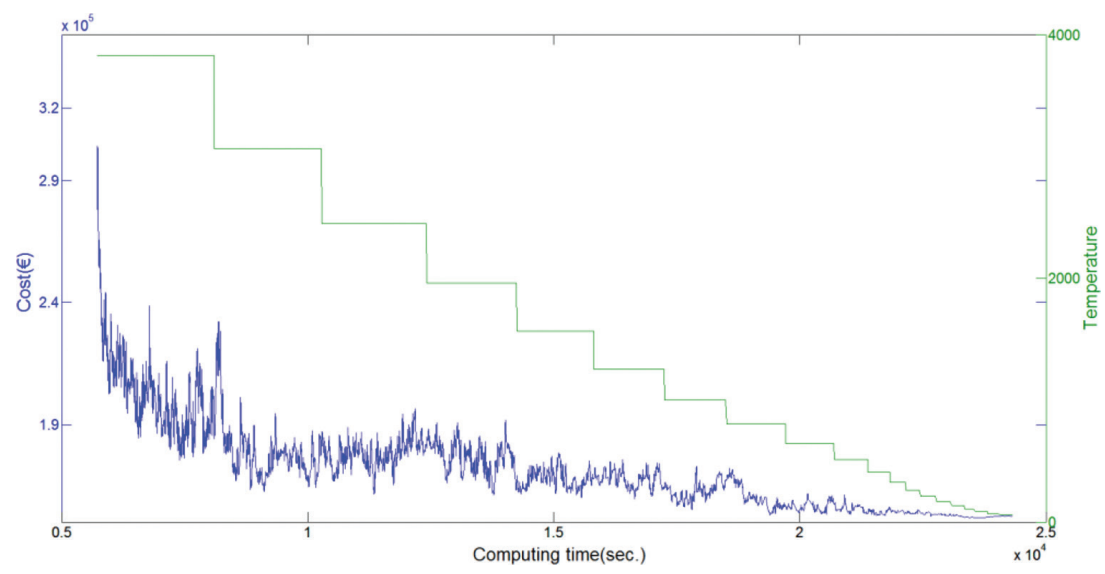

Figure 4:Histogram showing 500 cost-optimized SAMO2 results

Table 3 summarizes the best solution for each acceptance criterion when the main span length is $50 \mathrm{~m}$. The typical evolution for the SAMO2 is shown in Fig. 4. The algorithm allows initially high cost increments, and as the temperature is reduced the objective function converges to the minimum. Note that the evolution progresses gradually. This is justified by the small number of acceptances at the beginning, due to the probability of rejecting better solutions. However, this pattern enables unexplored regions to be searched and finally better solutions to be found. Therefore, this algorithm is used in the following studies.

\section{CONCRETE STRENGTH PARAMETRIC STUDY}

In this study, the effect of concrete compressive strength, ranging between 35 and $100 \mathrm{MPa}$, was evaluated. The optimal solutions according to this parameter were analyzed for the $50-\mathrm{m}$ case. First, note that the searching process obtained better cost results when concrete strength was studied as a fixed parameter. Likewise, findings for high-strength concrete improved in this study. This happens when the parameter presents the best results far from the normal search.

Figure 5 illustrates three linear relations between the cost per square meter of the deck and the concrete strength $\left(f_{c k}\right)$. Firstly, an inverse correlation up to $60 \mathrm{MPa}\left(\mathrm{C}=-0.7759 f_{c k}+\right.$ 369.87). Secondly, a small variation between $60 \mathrm{MPa}$ and $70 \mathrm{MPa}\left(\mathrm{C}=-0.0915 f_{c k}+329.49\right)$. Finally, a cost increment after $70 \mathrm{MPa}\left(\mathrm{C}=0.4359 f_{c k}+292.95\right)$. Table 4 shows that the depth and the amount of concrete presented a linear fit up to $60 \mathrm{MPa}$. Therefore, increasing concrete strength leads to a depth reduction and consequently, less concrete is needed. However, the 


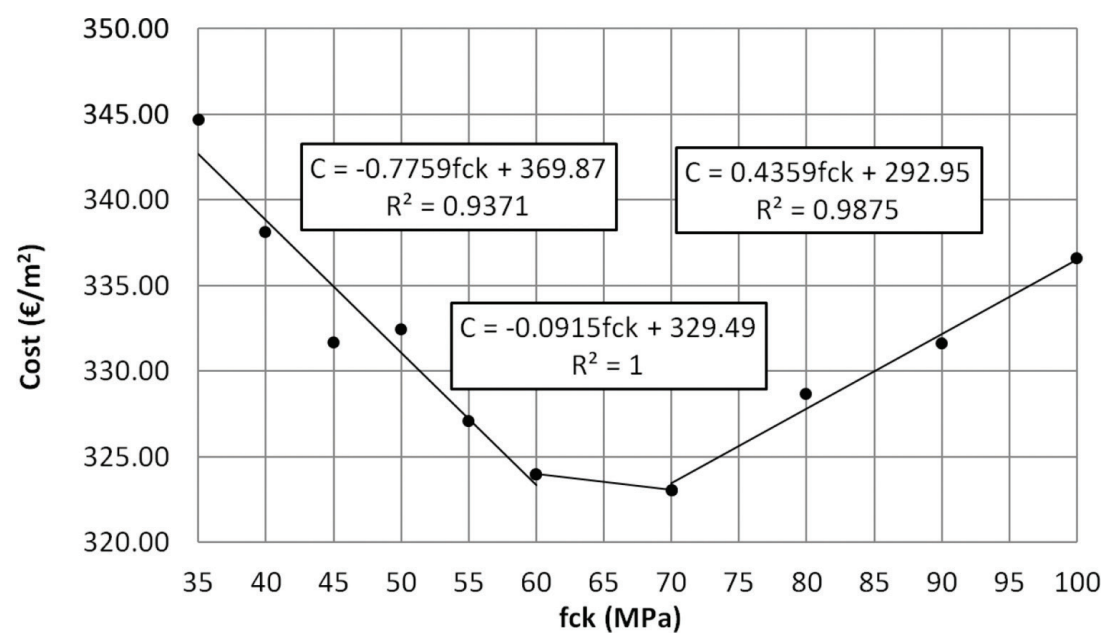

Figure 5: Mean cost per $\mathrm{m}^{2}$ of deck according to the concrete strength

Table 4: Mean measurements for concrete compressive strength study

\begin{tabular}{llllll}
\hline $\begin{array}{l}f_{c k} \\
(\mathrm{MPa})\end{array}$ & $h(\mathrm{~m})$ & $\begin{array}{l}\text { Concrete } \\
\left(\mathrm{m}^{3} / \mathrm{m}^{2}\right)\end{array}$ & $\begin{array}{l}\text { Post-tensioned } \\
\text { steel }\left(\mathrm{kg} / \mathrm{m}^{2}\right)\end{array}$ & $\begin{array}{l}\text { Longitudinal } \\
\text { reinforcement }\left(\mathrm{kg} / \mathrm{m}^{2}\right)\end{array}$ & $\begin{array}{l}\text { Transverse } \\
\text { reinforcement }\left(\mathrm{kg} / \mathrm{m}^{2}\right)\end{array}$ \\
\hline 35 & 1.56 & 0.58 & 22.20 & 23.37 & 43.70 \\
40 & 1.45 & 0.55 & 23.23 & 21.16 & 43.79 \\
45 & 1.35 & 0.52 & 22.95 & 20.55 & 45.05 \\
50 & 1.31 & 0.51 & 22.81 & 19.51 & 49.76 \\
55 & 1.27 & 0.50 & 21.97 & 18.80 & 49.34 \\
60 & 1.25 & 0.49 & 21.83 & 18.24 & 49.27 \\
70 & 1.25 & 0.49 & 21.55 & 18.35 & 49.35 \\
80 & 1.25 & 0.49 & 22.53 & 18.47 & 52.63 \\
90 & 1.25 & 0.49 & 22.67 & 18.00 & 55.23 \\
100 & 1.25 & 0.49 & 22.67 & 18.19 & 59.35 \\
\hline
\end{tabular}

depth remained constant between $70 \mathrm{MPa}$ and $100 \mathrm{MPa}$ for geometrical reasons. Analyzing the consequences for reinforcement, the reduction in longitudinal reinforcement can be noted. Transverse reinforcement increases with concrete strength to reach the minimum required by the code [22] for confining requirements. Concerning post-tensioned steel, there is no clear relation with concrete strength. Conclusively, the use of $70 \mathrm{MPa}$ concrete reduces the cost by $6.3 \%$ and the amount of concrete by $14.7 \%$, compared with $35 \mathrm{MPa}$ concrete. It is worth noting that decreasing concrete production not only involves cost minimization but also implies an environmental and esthetic benefit. However, a detailed study must be undertaken to examine the $\mathrm{CO}_{2}$ increment in high-strength concrete due to the cement increment, since the manufacture of Portland cement contributes large amounts of $\mathrm{CO}_{2}[7,35]$.

\section{CONCLUSIONS}

In this paper, the optimum design of a post-tensioned concrete box-girder pedestrian deck is evaluated. A program, which analyzes the structure, is extended to evaluate and optimize the 
total cost. The SAMO2 algorithm, which combines SA with a mutation operator, show to be an efficient procedure for the optimum design of the economic solutions. The calibrated method involves random variation of up to $50 \%$ of the variables, the initial temperature by Medina's method, Markov chains of 5000 iterations, a cooling coefficient of 0.80 and a stop criterion of three Markov chains without improvement. The local optima found by this SAMO2 are extreme values that fit a three-parameter Weibull distribution, $\gamma$ being an estimate of the global optimum that this algorithm could reach. The best value obtained by SAMO2 differed only $0.34 \%$ compared to the theoretical minimum value. The results are quite encouraging and suggest that this approach may easily be adapted to other optimization problems. On the other hand, highstrength concrete decreases the depth and the amount of concrete, which in turn, results in a cost reduction. Three linear functions may be used to describe the general relationship between the cost per square meter of the deck and the concrete strength. An inverse correlation up to 60 $\mathrm{MPa}$ and a cost increment after 70MPa. When the depth can no longer be reduced for geometrical reasons, the concrete strength increment is not effective. Thus, concrete strength should be increased in longer decks with greater depths. Besides, this effect has positive consequences of reducing the extraction of natural resources and improving the bridge esthetics.

\section{ACKNOWLEDGEMENTS}

The Spanish Ministry of Economy and Competitiveness along with FEDER funding (Project BIA2014-56574-R and Project BIA2017-85098-R) financially supported this research.

\section{REFERENCES}

[1] Yepes, V., Díaz, J., González-Vidosa, F. \& Alcalá, J.. Statistical characterization of prestressed concrete road bridge decks. Revista de la Construcción, 8(2), pp. 95-108, 2009.

[2] Aparicio, A.C., Casas, J.R. \& Ramos, G., Computer aided design of prestressed concrete highway bridges. Computers \& Structures, 60(6), pp. 957-969, 1996. https://doi.org/10.1016/0045-7949(96)00033-8

[3] Hassanain, M.A. \& Loov, R.E., Cost optimization of concrete bridge infrastructure. Canadian Journal of Civil Engineering, 30(5), pp. 841-849, 2003. https://doi.org/10.1139/103-045

[4] Penadés-Plà, V., García-Segura, T., Martí, J.V. \& Yepes, V., A review of multi-criteria decision making methods applied to the sustainable bridge design. Sustainability, 8(12), pp. 1295, 2016. https://doi.org/10.3390/su8121295

[5] Hernández, S., Fontan, A.N., Díaz, J. \& Marcos, D., VTOP. An improved software for design optimization of prestressed concrete beams. Advances in Engineering Software, 41(3), pp. 415-421, 2010. https://doi.org/10.1016/j.advengsoft.2009.03.009

[6] Cohn, M.Z. \& Dinovitzer, A.S., Application of structural optimization. Journal of Structural Engineering, 120(2), pp. 617-649, 1994. https://doi.org/10.1061/(asce)0733-9445(1994)120:2(617)

[7] García-Segura, T., Yepes, V., Martí, J.V. \& Alcalá, J., Optimization of concrete I-beams using a new hybrid glowworm swarm algorithm. Latin American Journal of Solids and Structures, 11(7), pp. 1190-1205, 2014. https://doi.org/10.1590/s1679-78252014000700007

[8] García-Segura, T., Yepes, V., Alcalá, J. \& Pérez-López, E., Hybrid harmony search for sustainable design of post-tensioned concrete box-girder pedestrian bridges. Engineering Structures, 92, pp. 112-122, 2015. https://doi.org/10.1016/j.engstruct.2015.03.015 
[9] Hasançebi, O. \& Kazemzadeh Azad, S., Improving computational efficiency of batinspired algorithm in optimal structural design. Advances in Structural Engineering, 18(7), pp. 1003-1015, 2015. https://doi.org/10.1260/1369-4332.18.7.1003

[10] Kaveh, A. \& Mahjoubi, S., Design of multi-span steel box girder using lion pride optimization algorithm. Smart Structures and Systems, 20(5), pp. 607-618, 2017.

[11] Mokarram, V. \& Banan, M.R., A new PSO-based algorithm for multi-objective optimization with continuous and discrete design variables. Structural and Multidisciplinary Optimization, 57(2), pp. 509-533, 2018. https://doi.org/10.1007/s00158-017-1764-7

[12] Lieu, Q.X., Do, D.T.T. \& Lee, J., An adaptive hybrid evolutionary firefly algorithm for shape and size optimization of truss structures with frequency constraints. Computers \& Structures, 195, pp. 99-112, 2018.

https://doi.org/10.1016/j.compstruc.2017.06.016

[13] Carbonell, A., González-Vidosa, F. \& Yepes, V., Design of reinforced concrete road vault underpasses by heuristic optimization. Advances in Engineering Software, 42(4), pp. 151-159, 2011.

https://doi.org/10.1016/j.advengsoft.2011.01.002

[14] Martínez-Martín, F.J., González-Vidosa, F., Hospitaler, A. \& Yepes, V., Multi-objective optimization design of bridge piers with hybrid heuristic algorithms. Journal of Zhejiang University-SCIENCE A, 13(6), pp. 420-432, 2012. https://doi.org/10.1631/jzus.a1100304

[15] Luz, A., Yepes, V., González-Vidosa, F. \& Martí, J.V., Design of open reinforced concrete abutments road bridges with hybrid stochastic hill climbing algorithms. Informes de la Construcción, 67(540), pp. e114, 2015.

https://doi.org/10.3989/ic.14.089

[16] Yepes, V., García-Segura, T. \& Moreno-Jiménez, J.M., A cognitive approach for the multi-objective optimization of RC structural problems. Archives of Civil and Mechanical Engineering, 15(4), pp. 1024-1036, 2015. https://doi.org/10.1016/j.acme.2015.05.001

[17] Martí, J.V., García-Segura, T. \& Yepes, V., Structural design of precast-prestressed concrete U-beam road bridges based on embodied energy. Journal of Cleaner Production, 120, pp. 231-240, 2016. https://doi.org/10.1016/j.jclepro.2016.02.024

[18] Yepes, V., Martí, J.V., García-Segura, T. \& González-Vidosa, F., Heuristics in optimal detailed design of precast road bridges. Archives of Civil and Mechanical Engineering, 17(4), pp. 738-749, 2017. https://doi.org/10.1016/j.acme.2017.02.006

[19] Torres-Machí, C., Yepes, V., Alcalá, J. \& Pellicer, E., Optimization of high-performance concrete structures by variable neighborhood search. International Journal of Civil Engineering, 11(2), pp. 90-99, 2013.

[20] BEDEC PR/PCT ITEC Materials Database, Catalonia Institute of Construction Technology, available at www.itec.cat (Accessed 10 September 2017)

[21] Schlaich, J. \& Scheff H., Concrete Box-girder Bridges, International Association for Bridge and Structural Engineering: Zürich, Switzerland, 1982.

[22] Fomento, M., IAP-98: Code on the actions for the design of road bridges, Ministerio de Fomento, Madrid, Spain, 1998. 
[23] Fomento, M., EHE-08: Code on structural concrete, Ministerio de Fomento, Madrid, Spain, 2008.

[24] Fomento, M., Recommendations for steel-concrete composite road bridges project, Ministerio de Fomento, Madrid, Spain, 1995.

[25] Kirkpatrick, S., Gelatt, C.D. \& Vecchi, M.P., Optimization by simulated annealing. Science, 220(4598), pp. 671-680, 1983.

https://doi.org/10.1126/science.220.4598.671

[26] Černý, V., Thermodynamical approach to the traveling salesman problem: An efficient simulation algorithm. Journal of Optimization Theory and Applications, 45(1), pp. 41-51, 1985. https://doi.org/10.1007/bf00940812

[27] Dreo, J., Petrowsky, A., Siarry, P. \& Taillard, E., Metaheuristics for hard optimization. Methods and case studies, Springer, Berlin (Heidelberg), 2006.

[28] Holland, J.H., Adaptation in Natural and Artificial Systems, Ann Arbor MI University of Michigan Press, 1975.

[29] Castilho, V.C. de, El Debs, M.K. \& Carmo Nicoletti, M. do, Using a modified genetic algorithm to minimize the production costs for slabs of precast prestressed concrete joists. Engineering Applications of Artificial Intelligence, 20(4), pp. 519-530, 2007. https://doi.org/10.1016/j.engappai.2006.09.003

[30] Martí, J.V., Gonzalez-Vidosa, F., Yepes, V. \& Alcalá, J., Design of prestressed concrete precast road bridges with hybrid simulated annealing. Engineering Structures, 48, pp. 342-352, 2013. https://doi.org/10.1016/j.engstruct.2012.09.014

[31] Junghans, L. \& Darde, N., Hybrid single objective genetic algorithm coupled with the simulated annealing optimization method for building optimization. Energy and Buildings, 86, pp. 651-662, 2015. https://doi.org/10.1016/j.enbuild.2014.10.039

[32] Medina, J.R., Estimation of Incident and Reflected Waves Using Simulated Annealing. Journal of Waterway, Port, Coastal, and Ocean Engineering, 127(4), pp. 213-221, 2001. https://doi.org/10.1061/(asce)0733-950x(2001)127:4(213)

[33] Payá-Zaforteza, I., Yepes, V., González-Vidosa, F. \& Hospitaler, A., On the Weibull cost estimation of building frames designed by simulated annealing. Meccanica, 45(5), pp. 693-704, 2010. https://doi.org/10.1007/s11012-010-9285-0

[34] Carbonell, A., Yepes, V. \& González-Vidosa, F., Automatic design of concrete vaults using iterated local search and extreme value estimation. Latin American Journal of Solids and Structures, 9(6), pp. 675-689, 2012.

[35] García-Segura, T., Yepes, V. \& Alcalá, J., Life cycle greenhouse gas emissions of blended cement concrete including carbonation and durability. International Journal of Life Cycle Assessment, 19(1), pp. 3-12, 2014. https://doi.org/10.1007/s11367-013-0614-0 